\title{
A dinâmica da rede hidrográfica da bacia do rio Sapucaia, Japaratuba/Pirambu-SE.
}

A dynamic network of watershed Sapucaia river basin, Japaratuba / Pirambu-SE.

SANTANA $^{1}$, F. S.; ALVES ${ }^{2}$, N. M. S.; $\mathrm{MELO}^{3}$, I. S.

fran_17ss@hotmail.com

\begin{abstract}
Resumo
Este artigo objetiva abordar a dinâmica da Bacia Hidrográfica do Rio Sapucaia em interação com os elementos que compõe esse sistema fluvial. Os estudos foram desenvolvidos de acordo com a concepção sistêmica e integrada (BERTRAND, 1972; BERTALANFFY, 1973; TRICART, 1977), com ênfase na análise de aspectos morfométricos (CRISTOFOLLETI, 1980), que conduzem a dinâmica da rede hidrográfica em suas interações com os condicionantes ambientais. As variáveis analisadas permitiram reavaliar os conhecimentos de Fontes (1984) sobre os recursos hídricos desta bacia hidrográfica costeira, de grande relevância para as atividades da população dos municípios de Japaratuba e Pirambu. Tais informações podem constituir subsídios importantes para o planejamento e gestão destes recursos.
\end{abstract}

Palavras-chave: Bacia do Rio Sapucaia, Análise Morfométrica e Dinâmica Hidrográfica.

\begin{abstract}
This article aims to address the dynamics of Basin Sapucaia River in interaction with the elements that make this river system. The studies were developed according to the systemic and integrated design (BERTRAND, 1972; BERTALANFFY, 1973; TRICART, 1977), with emphasis on the analysis of morphometric (CRISTOFOLLETI, 1980), leading the dynamics of the river system in their interactions with environmental conditions. The variables analyzed allowed re-evaluate the sources of knowledge (1984) on water resources of this coastal basin of great relevance to the activities of the population in the municipalities of Japaratuba and Pirambu. Such information may be important information for planning and management of these resources.
\end{abstract}

Keywords: Basin Sapucaia, River Morphometric Analysis and Hydrographic Dynamics.

\section{INTRODUÇÃO}

No decorrer da história da humanidade, a água enquanto recurso natural tem se tornado um bem cada vez mais escasso. Diante desta realidade, são elaborados planos de gestão para o uso e controle deste recurso fundamental para vida. Assim, a sociedade, vem tomando consciência e tem buscado maneiras de planejar o uso e gerir os recursos hídricos de modo a evitar o seu esgotamento ou comprometimento da sua qualidade e distribuição. Dessa forma, desenvolver estudos sobre Bacia Hidrográfica é de extrema importância tanto para a gestão dos recursos hídricos, como para o planejamento ambiental.

$\mathrm{Na}$ análise de uma Bacia Hidrográfica devem ser considerados, particularmente, dois aspectos: um de ordem natural e outro de ordem antrópica. As interferências propiciadas pela ação do homem podem ser verificadas em diferentes ações- construção de barragens ao longo dos cursos dos rios causando a regularização das vazões; instalação de equipamentos para a captação de água 
com finalidade de usos múltiplos - abastecimento da população, projetos de irrigação, entre outros; ocupação do solo com uso de técnicas de manejo; remoção da vegetação; etc.

Estas interferências acarretam em alterações na dinâmica do sistema fluvial, contribuindo, quase sempre, para a ocorrência de problemas ambientais e sociais, como: assoreamento dos canais; processos erosivos nas margens; comprometimento das condições de sobrevivência para as populações ribeirinhas; prejuízos para o ecossistema aquático; entre outros.

A Bacia Hidrográfica do Rio Sapucaia é uma pequena bacia costeira cuja área está inserida nos municípios de Japaratuba e Pirambu, no litoral norte do estado de Sergipe, correspondendo a uma área de 69,1 km². Conforme estudos da Secretária de Estado do Meio Ambiente e dos Recursos Hídricos (SEMARH), esta Bacia integra a unidade de planejamento UP-3/GC-1, do Grupo de Pequenas Bacias dos Rios Costeiros que deságuam no oceano Atlântico.

Diante dessas considerações, o estudo proposto objetiva analisar os principais elementos que compõem a dinâmica da Bacia Hidrográfica do Rio Sapucaia, com ênfase na análise dos parâmetros morfométricos.

\section{METODOLOGIA}

A realização desse estudo exigiu revisão bibliográfica para a construção do referencial teórico; levantamento de dados e informações sobre a área de estudo, material cartográfico fotografias aéreas, mapas topográficos e temáticos, e imagem de satélite.

Foram utilizadas ferramentas tecnológicas do SIG (Sistema de Informação Geográfica) a partir do software ArcGIS 9.3 que permitiu a delimitação da Bacia Hidrográfica do Rio Sapucaia, a hierarquização dos canais - com a construção de shapes de linha para a reconstituição da rede de drenagem sobre as ortofotocartas, a partir da finalização dos shapes foi feito o layout. Após a elaboração elou manipulação digital de mapas e imagens, facilitando a análise de informações espaciais.

Na construção da base cartográfica foram utilizadas a folha topográfica Japaratuba (SC.24Z-B-V), escala 1:100.000, Superintendência do Desenvolvimento do Nordeste (SUDENE, 1974); Mapa de Geologia e Recursos Minerais do Estado de Sergipe, escala 1: 250.000 (SANTOS et al., 1997); Mapas temáticos - geologia, geomorfologia, vegetação, recursos hídricos, etc. - escala 1: 1. 000. 000 e texto do Projeto RADAMBRASIL (BRASIL, 1983); Mapa de solos, escala 1: 100.000, folha Japaratuba (SC. 24-Z-B-V),(EMBRAPA, 1999); Mapas do Atlas Digital sobre Recursos Hídricos de Sergipe, PROJETO Cadastro da Infra-estrutura Hídrica do Nordeste, Companhia de Prospecção dos Recursos Minerais, disponível em CD, (SEPLANTEC/SE, 2002); Fotografias aéreas, coloridas, escala 1: 25.000, fotoíndice 1, escala 1: 100.000, vôo - 12/2003, Base 
Cartográfica dos Municípios Litorâneos de Sergipe, em destaque para o município de Pirambu, SEPLAN/SE.

Foram realizadas visitas a órgãos públicos como a: SEMARH/SE (Secretaria de Estado do Meio Ambiente e Recursos Hídricos de Sergipe), a CODISE (Companhia de Desenvolvimento Industrial e de Recursos Minerais de Sergipe), a EMBRAPA (Empresa Brasileira de Pesquisa Agropecuária), a SEPLAN (Secretaria de Estado do Planejamento) e o IBGE (Instituto Brasileiro de Geografia e Estatística).

Foram realizados trabalhos de campo para a observação integrada das características dos elementos que constituem o sistema ambiental, e particularmente, da rede hidrográfica. $\mathrm{Na}$ análise da bacia hidrográfica foram considerados e aplicados parâmetros morfométricos indicados por Christofoletti (1980). Estas informações poderão subsidiar a gestão dos recursos hídricos.

\section{RESULTADOS E DISCUSSÃO}

\section{1- Caracterização da área de estudo}

A Bacia Hidrográfica compreende uma área drenada por um rio principal e os seus afluentes e sub-afluentes. O sistema fluvial é formado por diversas condicionantes naturais que se interrelacionam num determinado espaço, configurando um geossistema (BERTRAND, 2004). Assim, pode-se compreender a Bacia Hidrográfica do Rio Sapucaia como um geossistema (BERTRAND, 2004), uma vez que sua dinâmica é definida a partir dos processos desencadeados na dinâmica do sistema ambiental regional. Deste modo, se faz necessário a análise integrada das condicionantes atuantes neste geossistema: clima, geologia, geomorfologia, vegetação e a ação antrópica, que influenciam o comportamento dos corpos hídricos da bacia.

O Estado de Sergipe apresenta três tipos de clima: subúmido, de transição semi-árido e semiárido. No que se refere à escala local, ou seja, a área da Bacia do Rio Sapucaia, nos municípios de Japaratuba e Pirambu, se insere no tipo climático Megatérmico Subúmido. Este clima tem como características um nível de precipitação que oscila entre 1200 e 1500 mm anuais e uma estação seca de pequena duração, apresentando chuvas concentradas no período outono-inverno, quando a atuação da $\mathrm{mPa}$ ocasiona instabilidade e precipitações fortes. As temperaturas médias oscilam entre $23^{\circ} \mathrm{C}$ e $28^{\circ}$, observando-se média anual de $25^{\circ} \mathrm{C}$ (FONTES, 1984; ALVES, 2010).

Com relação à geologia, a área deste estudo é parte integrante da bacia sedimentar SergipeAlagoas, caracterizada por unidades litológicas englobadas pelas Formações Superficiais Continentais Cenozóicas, compreendendo o Grupo Barreiras e depósitos quaternários aluviais, marinhos e eólicos (RADAM, 1983; SANTOS et al.,1998). 
O Grupo Barreiras constitui uma cobertura sedimentar terrígena continental, de idade pliopleistocênica. Os sedimentos areno-argilosos, poucos consolidados e mal selecionados, de granulometria diversificada, apresentam camadas de siltito, argila e cascalho; além de grande variedade na coloração, variando do avermelhado ao esbranquiçado. A área de abrangência do Grupo Barreiras verifica-se na área do alto e médio curso do Rio Sapucaia.

Os depósitos holocênicos estão distribuídos no setor do baixo curso do Rio Sapucaia, incluindo o ambiente praial onde se encontra sua foz. Tais depósitos resultam de eventos da história geológica, com destaque para os ciclos transgressivos e regressivos ocorridos durante o Quaternário.

Geomorfologicamente, na área da Bacia Hidrográfica do Rio Sapucaia, destacam-se duas unidades: os Tabuleiros Costeiros e a Planície Costeira.

Os Tabuleiros Costeiros constituem uma unidade que se estende por todo o litoral nordestino. Estas morfologias estão associadas aos sedimentos do Grupo Barreiras e apresentam variações altimétricas e feições onde se destacam os topos, as vertentes e vales.

A Planície Costeira constitui a segunda unidade geomorfológica, estando representada pelo campo de dunas costeiras ativas e embrionárias e, lençóis de areia. O aporte sedimentar na Planície Costeira é decorrente da ação fluvial, marinha e eólica.

A cobertura vegetal encontrada na área de estudo é condicionada pelo tipo climático e pelas características texturais dos tipos de solos. A vegetação possui um papel importante na proteção do solo em relação ao desenvolvimento dos processos morfogenéticos, pois atua amenizando ou retardando a sua erosão.

Atualmente, o fator antrópico é identificado como um dos mais importantes na alteração das formações vegetais originais - Floresta Estacional Semidecidual, Cerrado, Restinga e Campo de Várzea. As atividades econômicas, particularmente a agropecuária e mineração contribuem para a degradação da vegetação.

$\mathrm{Na}$ Bacia do Rio Sapucaia podem ser encontrados setores colonizados por manchas remanescentes de Mata Atlântica em diferentes estágios de antropização. As manchas de Cerrado têm sua ocorrência condicionada pelo tipo climático, que apresenta duas estações definidas - uma seca e outra chuvosa -, e pela presença dos sedimentos arenosos nos topos tabulares.

Nas áreas dos vales dos rios e depressões da planície de inundação dos cursos d'água verifica-se a presença de vegetação higrófila e/ou hidrófila em razão da proximidade do lençol freático da superfície.

No geossistema Bacia Hidrográfica do Rio Sapucaia, observam-se os efeitos da ação antrópica, sobre os demais elementos deste sistema ambiental. Estas intervenções correspondem - a 
construção de barramentos ao longo dos cursos dos rios para implantação de atividades econômicas; instalações de equipamentos para captação de água para projetos de irrigação e abastecimento da população; uso de técnicas e manejo inadequado do solo; remoção da vegetação nativa para uso agropecuário do solo, entre outros. As repercussões destas ações provocam desequilíbrios no conjunto do sistema, tornando-se evidentes aspectos de assoreamento nos canais de drenagem, da ação do escoamento das águas pluviais, desenvolvimento de ravinas e sulcos nas vertentes, descaracterização paisagística com os cortes nas vertentes das colinas para a extração das areias e seixos, entre outros.

\section{2- Análise Morfométrica da Bacia do Rio Sapucaia}

Os estudos desenvolvidos na Bacia do Rio Sapucaia permitiram a realização da análise morfométrica, envolvendo as variáveis principais e a elaboração do mapa de Hierarquia da Rede de Drenagem, que serviu de base para a mesma. A caracterização morfométrica de uma bacia hidrográfica é de grande importância cientifica e necessária à gestão dos recursos hídricos, uma vez que a mesma proporciona informações sobre o comportamento da rede de drenagem e a dinâmica ambiental na área da bacia.

A Bacia do Rio Sapucaia apresenta um escoamento do tipo exorreico, já que a mesma deságua diretamente no mar, no município de Pirambu e se constitui numa Bacia de $5^{\mathrm{a}}$ ordem. No setor noroeste do alto curso do rio os canais apresentam um padrão subparalelo, no setor sudoeste predomina o padrão dentrítico, tipicamente desenvolvido sobre rochas de grande resistência ou estruturas sedimentares horizontais, como se verifica no Grupo Barreiras. Estruturalmente, a área sofre influência das falhas de Piranhas de Alagamar de direção nordeste - sudoeste. Assim, feixes de falhas e fraturas associados a estas condicionam a orientação dos tributários que integram a rede de drenagem, resultando num padrão misto (MAPA 01). 


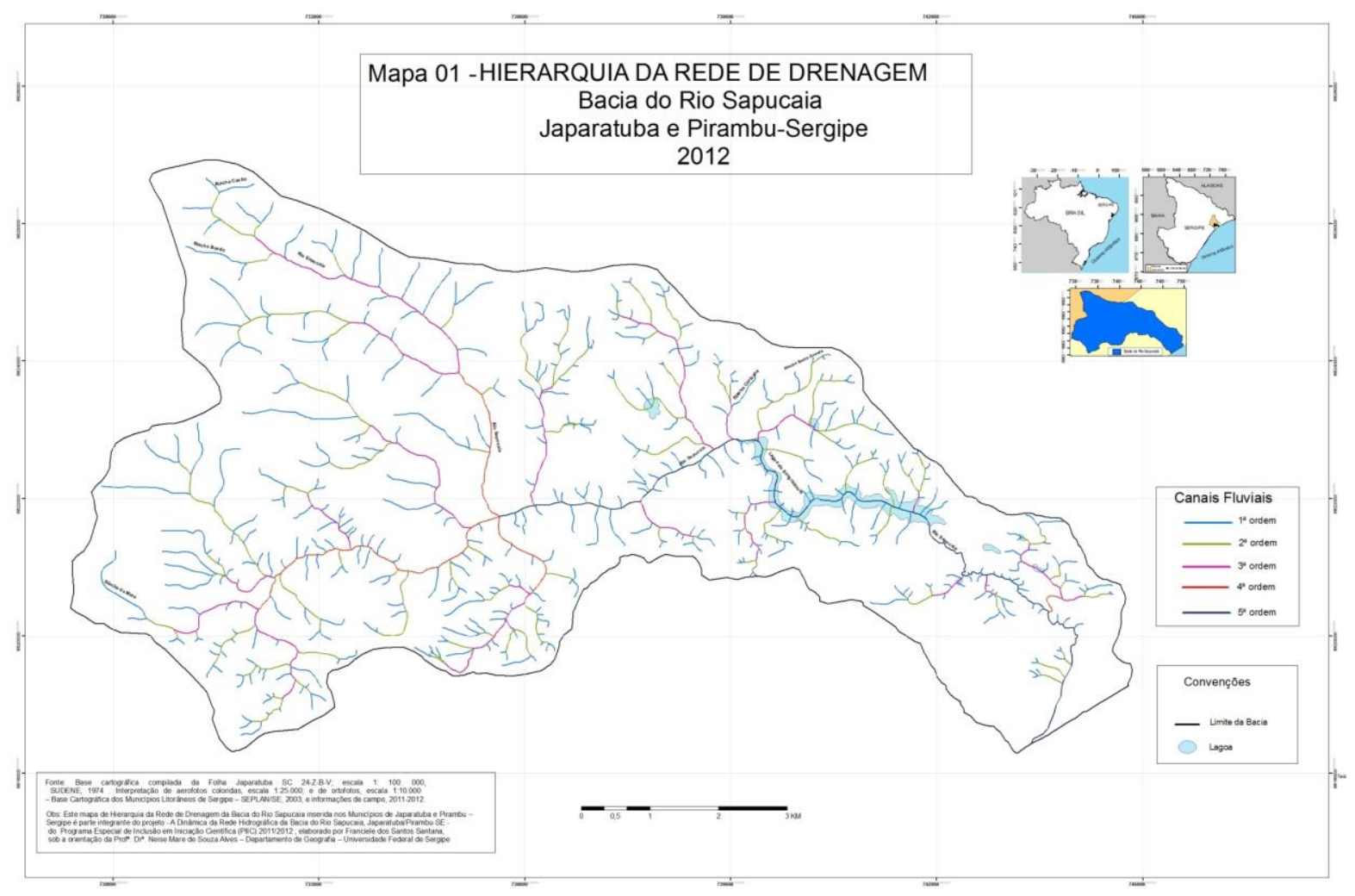

A Bacia do Rio Sapucaia é formada por canais fluviais de regime temporário e perene, estreitos e pouco profundos, sinuosos, com setores anastomosados e baixa potencialidade hídrica superficial. As margens são mal definidas e geralmente desprovidas de mata ciliar. O Rio Sapucaia, embora de pequena vazão drena durante todo o ano.

A análise morfométrica de uma bacia hidrográfica é de grande importância cientifica e necessária ao planejamento e gestão dos recursos hídricos, uma vez que proporciona o estudo de variáveis e aspectos do sistema ambiental. Assim, a partir destes dados são obtidas informações sobre o comportamento da rede de drenagem e a dinâmica ambiental na área da bacia. De acordo com Christofoletti (1980) a análise morfométrica abrange vários parâmetros.

A Magnitude $(\mathrm{M})$ é representada pelo número de nascentes numa bacia (CHRISTOFOLETTI, 1980). Assim, na Bacia em estudo foram identificados 382 canais de primeira ordem.

O Perímetro (P) expressa o comprimento total da linha do divisor de águas (CHRISTOFOLETTI, 1980). Para a Bacia em estudo foi constatado o valor de 46, $6 \mathrm{~km}$.

A Frequência ou densidade de segmentos $\left(\mathrm{Fs}=\frac{\mathrm{ni}}{A}\right)$ corresponde ao somatório de todas as ordens da bacia por unidade de ordenação (CHRISTOFOLETTI, 1980). A Bacia do Rio Sapucaia foi classificada como sendo de $5^{\circ}$ ordem, apresentando a frequência 7,2 .

A Área da Bacia em análise totaliza $69,1 \mathrm{~km}^{2}$. 
A Extensão do Rio principal é avaliada a partir da nascente mais longa e distante da foz (CHRISTOFOLETTI, 1980). Para o Rio Sapucaia cuja nascente se encontra no Povoado Sapucaia, município de Japaratuba/SE. Este possui uma extensão de 20, 76 km.

O Índice de Circularidade $\left(\mathrm{Ic}=\frac{\mathrm{A}}{\mathrm{Ac}}\right)$ representa a relação existente entre a área da bacia e a área do círculo do mesmo perímetro, sendo o cálculo indicativo de maior ou menor tendência para enchente (CHRISTOFOLETTI, 1980). Para esta variável existem valores de referência que são indicativos para maior ou menor probabilidade a enchentes: < 0,50, não sujeita a enchentes; 0,50 a 0,75, tendência mediana; 0,75 a 1,00, sujeita a enchentes. Para a Bacia estudada verificou-se Ic de 0,40. Considerando que a forma da Bacia do Rio Sapucaia é alongada e possui baixo Ic, é pequena a probabilidade de enchentes.

A Densidade de Drenagem $\left(\mathrm{Dd}=\frac{\mathrm{L}}{\mathrm{A}}\right.$ ) correlaciona o comprimento total dos canais com a área da bacia hidrográfica, para este cálculo são considerados os rios perenes e intermitentes (CHRISTOFOLETTI, 1980). O resultado obtido expressa a disponibilidade de canais de escoamento para o fluxo de água e materiais dentríticos e o grau de dissecação do relevo resultante da atuação da rede de drenagem (CHRISTOFOLETTI, 1980).

Quadro 01- Comprimento dos canais por ordem de hierarquia.

\begin{tabular}{|c|c|c|}
\hline Ordem & $\mathrm{N}^{\mathbf{o}}$ de Canais & Comprimento $(\mathrm{km})$ \\
\hline $1^{\mathrm{a}}$ ordem & 382 & 110,81 \\
\hline $2^{\mathrm{a}}$ ordem & 90 & 48,49 \\
\hline $3^{\mathrm{a}}$ ordem & 20 & 28,83 \\
\hline $4^{\mathrm{a}}$ ordem & 4 & 9,07 \\
\hline $5^{\mathrm{a}}$ ordem & 1 & 13,11 \\
\hline TOTAL & 497 & 210,31 \\
\hline
\end{tabular}

Fonte: Elaboração e organização dos dados pela autora - 2012.

Quadro 02 - Classes de interpretação para os valores da densidade de drenagem.

\begin{tabular}{|c|c|}
\hline Classes de valores $\left(\mathrm{km}\left(\mathrm{km}^{2}\right)^{-1}\right.$ & Interpretação \\
\hline Menor que 7,5 & Baixa densidade de drenagem \\
\hline Entre 7,5 e 10,0 & Média densidade de drenagem \\
\hline Maior que 10,0 & Alta densidade de drenagem \\
\hline
\end{tabular}

Fonte: Christofoletti (1969 apud Silva 2003, p. 98). 
A partir da realização dos cálculos necessários para aferição da Densidade de Drenagem, foi obtido para a Bacia do Rio Sapucaia o valor de 3,04, que a insere na classe de baixa densidade de drenagem. Esta constatação pode ser decorrente das características texturais do Grupo Barreiras e depósitos holocênicos, além da sazonalidade climática.

A Densidade Hidrográfica $\left(\mathrm{Dh}=\frac{\mathrm{N}}{\mathrm{A}}\right)$ representa a relação entre o número de rios e a área da bacia hidrográfica (CHRISTOFOLETTI, 1980). Para esta Bacia o resultado desta variável foi 5,52. Da mesma forma que a densidade de drenagem, a densidade hidrográfica é uma referência para analisar a textura da topografia.

\section{CONSIDERAÇÕES FINAIS}

A Bacia do Rio Sapucaia é uma unidade de paisagem resultante da interação entre os componentes naturais e o componente antrópico, portanto, a mesma se configura como um geossistema.

O homem se apropria da natureza utilizando os seus recursos com o intuito de suprir suas necessidades econômicas, gerando, quase sempre impactos e/ou desequilíbrios ambientais. Dessa forma, o homem é reconhecido como o principal agente transformador da paisagem.

$\mathrm{Na}$ área de estudo, o diagnóstico efetuado permitiu constatar a necessidade de práticas coerentes com o potencial de recursos naturais, uma vez que a ação antrópica é intensa principalmente, sobre os recursos hídricos. Estas práticas comprometem a dinâmica da rede hidrográfica, podendo interferir no desenvolvimento das atividades econômicas e no abastecimento da população.

Além disso, a análise morfométrica foi fundamental para a compreensão da dinâmica de uma bacia hidrográfica. Esta análise é importante para o conhecimento dos recursos hídricos, possibilitando a elaboração de planos de gestão, uma vez que com os estudos realizados obtêm-se dados que podem subsidiar outras análises.

\section{REFERÊNCIAS}

ALVES, N. M. S. Análise geoambiental e socioeconômica dos munícipios costeiros do litoral norte do estado de Sergipe - diagnóstico como subsídio ao ordenamento e gestão do território. 2010, 382f. ; II. Tese de doutorado (Doutorado em Geografia) - NPGEO, Universidade Federal de Sergipe, São Cristóvão, 2010.

BERTALANFFY, L. V. Teoria geral dos sistemas. 3. ed. Petrópolis: Vozes, 1977. 351 p.

BERTRAND, G. Paisagem e geografia física global: esboço metodológico.Revista RA'E GA, Curitiba, UFPR, no 8, p.141-152, 2004.

BRASIL. Ministério das Minas e Energia. Projeto RADAMBRASIL: folha SC.24/25 Aracaju/Recife: geologia, geomorfologia, pedologia, vegetação, uso potencial da terra. Rio de Janeiro, 1983. 851 p. (Levantamento de Recursos Naturais,30). 
CARVALHO, E. L.; MIRANDA, D. A importância da bacia hidrográfica como unidade de planejamento para a gestão ambiental integrada. Curso/Habilitação em Geografia (GED0611)Análise e Gestão de Bacias Hidrográficas, 2009. Disponível em:<http://www.webartigos.com/artigos/a-importancia-da-bacia-hidrografica-como-unidade-deplanejamento-para-a-gestaoambiental-integrada/23846/. Acesso em: 05 nov. 2011.

CASSETTI, V. Ambiente e apropriação do relevo. São Paulo: Contexto, 1991.

CHRISTOFOLETTI, A. Geomorfologia fluvial: o canal fluvial. São Paulo: 1981.

CHRISTOFOLETTI, A. Geomorfologia. $2^{\circ}$ Ed. São Paulo: Edgard Blucher, 1980.

CUNHA, S. B. ; GUERRA, A. J. T. Geomorfologia: exercícios, técnicas e aplicações. Rio de Janeiro: 2002.

FONTES, A. L. Geomorfologia da área de Pirambu e adjacências (Sergipe). S. d. 152f. Dissertação (Mestrado em Geociências) - Câmara de Ensino de Pós-Graduação e Pesquisa, Universidade Federal da Bahia, 1984.

SANTOS, R. A. dos. (Org.). et al. Geologia e recursos minerais do estado de Sergipe: texto explicativo do mapa geológico do estado de Sergipe. Brasília: CPRM; Aracaju: CODISE, 107 p. 1998. (Programa Levantamentos Geológicos Básicos do Brasil).

SOTCHAVA, V. B. O estudo de geossitemas: métodos em questão. São Paulo: IGUSP, 1977.

Recebido em: 14/08/2016

Aceito para publicação em: 01/10/2016 